\title{
ENTRE PERROS Y LOBOS. UN CHAPARRÓN DE INÚTILES CONSEJOS PARA EL REY D. SEBASTIÁN*
}

\author{
JOSÉ MiguEL MARTÍNEZ TORREJÓN \\ Queens College \& Graduate Center \\ City University of New York
}

Para Soledad Carrasco Urgoiti, in memoriam

Diríase que los tres poemas aquí publicados, de intenciones políticas muy concretas, estaban destinados a la vida efímera de los días en que nacieron. Sin embargo, se conservan en nada menos que siete manuscritos de los siglos XVI y XVII, separados por un lapso de cincuenta o sesenta años, y no podemos menos que sospechar que algunos testimonios más se encuentran no identificados, demostrando una abundante difusión de que muchos clásicos no gozaron. Hay que entender que no se trata de un caso aislado, sino de uno de los muchos poemas de disidencia política que circularon en su momento ${ }^{1}$.

Estamos en el decenio de reinado efectivo de Don Sebastián (1568-1578). La problemática personalidad del joven rey y las líneas maestras de su política se manifiestan en hechos que preocupan crecientemente a sus súbditos: rechazo de sus anteriores regentes, sumisión a su confesor y a su secretario, los hermanos Luís y Martim Gonçalves da Câmara, alejamiento progresivo de la nobleza y pueblo de su reino, descuido u obstrucción de los sucesivos planes para su matrimonio y atención obsesiva a su sueño de conquistar Berbería. Medio siglo después, Pero Roiz Soares, en su Memorial que contém todos os casos..., uno

\footnotetext{
* Agradezco a la Fundação Luso-Americana para o Desenvolvimento y a la Biblioteca Nacional de Portugal la ayuda concedida en el verano de 2005 para la necesaria investigación en Lisboa. Numerosos textos literarios de cariz político en torno al reinado de D. Sebastián verán la luz próximamente en el volumen que preparo sobre el tema, del cual este trabajo es un adelanto.

1 Sobre la abundante literatura portuguesa en castellano, y concretamente la de contenido político, me permito remitir a La littérature portugaise en langue castillaine, núm. monográfico de Arquivos, XLIV, 2002, así como a mis contribuciones a dicho volumen: «Prologue», ibid., págs. 3-9, y «Satire et Poésie de Circonstances autour de 1'union ibérique», ibid., págs. 165-181.
} 
de testimonios que han conservado estos Avisos, describió la situación de forma precisa, pese a confundir algunos datos:

El-rei a este tempo, todo seu desenho e inclinação era guerra e caça, dado que já o apetite da caça lhe ia passando, entrando no da guerra, como muitos desejos que parece lhos incertava Deus pera por si vir a dar tan gravíssimos castigos a Portugal, como adiante se verá, quais cuido nunca foram dados a reino algum. Os fidalgos neste tempo queixavam-se dele que os esquivava, não queria ver, maltratava de palavras e devassas que deles mandava tirar e que não comunicava mais que com o seu privado Cristóvão de Távora, moço e sem expiriência, e que dava de mão aos velhos, que a tinham muita, pera o poder aconselhar e que só os padres da Companhia reinavam com ele, dado que esta não era má conversação nem donde lhe podia vir senão muita vertude, como el-rei nosso senhor tinha aprendido deles, mas como viam que só eles eram o tudo e que por eles se governava el rei, juntamente e principal por o seu escrivão da puridade, Martim Gonçalves da Câmara, fidalgo vertuossíssimo que em tudo imitava os padres da Companhia, sacerdote de muita vertude e exemplo, não deixava por todas estas vias d'haver envejas nos fidalgos e queixarem-se que não deixavam tratar el-rei cos fidalgos nem conversá-los, e que queria que todos fossem religiosos como eles, o povo também ajudava esta queixa por nunca terem el-rei d'assento em Lisboa, e os ofícios andarem perdidos. Os pregadores nos púlpitos todo era cramarem com a mesma queixa dos fidalgos e do povo. Nesta confusão andava então o reino assaz desconsolado, do que cabia muita parte desta desconsolação à rainha, mãe do seu povo tanto mais como as mais que podia haver, e por todas as vias buscavam cada dia remédios e envenções pera amonestarem a el-rei com escritos, com trovas, entre as quais lhe fizeram as que se seguem, que lhe foram ter à mão. (cap. 29)

Roiz Soares fecha las trovas al principio del verano de 1574, es decir, antes de la partida de D. Sebastián para Tánger, el 15 de agosto del mismo año, e incluye seguidamente la primera de las series aquí publicadas, que habría sido entregada al rey para disuadirle de sus planes. Tanto la fecha como las circunstancias son verosímiles, pero hay que tener en cuenta que Roiz Soares escribe a más de medio siglo de distancia, y probablemente no tiene más fuente histórica al respecto que las mismas trovas, pues de ellas se puede inferir fácilmente cuanto dice. Barbosa Machado asegura que los Avisos le fueron entregados al rey en Évora, en octubre de 1572, el 24 de diciembre de 1572 y en Cuaresma de 1573 , respectivamente. No sabemos cuál es la fuente de información del gran polígrafo, quien puede estar simplemente extrapolando a partir de la primera de estas fechas, que aparece en el Cancionero de Madrid $(M)$, o especulando a partir de las circunstancias históricas, pues está comprobado que D. Sebastián estuvo en Évora en esas tres ocasiones ${ }^{2}$.

2 Diogo Barbosa Machado, Bibliotheca Lusitana [Lisboa, 1741-1759], Coimbra, Atlántida, 1965-1967, II, pág. 230. Una probable referencia a estas trovas se encuentra también en la Mis- 
En efecto, a pesar de que los poemas se nos han transmitido juntos en tres testimonios y en el mismo orden en que aquí se publican, su contenido permite concluir que pertenecen probablemente a dos o tres momentos distintos, y que no es ése el orden en que fueron compuestos: tanto el segundo como el tercero se refieren a sí mismos como continuaciones del primero; nunca hubo, pues, una serie de tres hasta que tardíamente fueron copiados juntos. El primero y el tercero se ocupan de satirizar el ascenso de los hermanos Cámara, quienes a partir de la peste grande de 1569 fueron insistentemente acusados de haberse apoderado de la persona del rey y mantenerlo lejos de Lisboa y de la relación con su corte, su abuela y sus hidalgos. Se incluye un amplio abanico de temas e imágenes presentes en documentación y literatura de los años 1570-1572: la caza como pretexto para no estar en la corte y como substitución del matrimonio; el rey, que debía ser buen pastor, se ha convertido en cazador y se deshace de sus mastines, fieles guardianes, para dejar el rebaño a «fieros lobos hambrientos». En contrapartida, el propio rey, como un salvaje, está solo, separado de su rebaño y en manos de los mismos lobos, imagen que podría estar emparentada con la de los perros que sin duda rodean al cazador y que, como a Acteón en Os Lusiadas (también de 1572), acabarán comiéndoselo; no se puede afirmar una relación directa entre ambas obras, pero cualquiera de ellas podría haberse inspirado en la otra. De particular interés es una carta anónima dirigida al confesor del rey, Luís Gonçalves da Câmara, que ha sido frecuentemente atribuida a Jerónimo Osório, y que en el mismo momento histórico se refiere exactamente a los mismos temas; las numerosas coincidencias con el primer Aviso, presentando a D. Sebastián como «rei montesinho (es decir, dedicado a la caza por el monte, pero también 'ferino', criado por lobos en lugar de padres) e que não vê nem conversa à gente de que mais se há de servir», podrían significar también algún tipo de conexión directa entre ambos textos anónimos ${ }^{3}$.

celânea de Miguel Leitão de Andrada: «E já antes disto lhe poseram a este rei em Almeirim, no assento de uma janela da câmara onde dormia, umas trovas ao modo pastoril, todas de advertimentos, as quaes achando-as ele as leo e as meteo na algibeira, e dizem fez algumas mudanças, assi em homens como em cousas. Que muitas vezes é utilíssimo diserem-se aos reis as verdades, ainda que amarguem, e buscarem-se pera isso modos, por quanto os aduladores, que de ordinário são os que lhe assistem, tomão mais de ordinário todos os caminhos de se lhe poderem dizer» (Miscelânea do sítio de N. Sra. da Luz do Pedrogão Grande, aparecimento de sua santa imagem, fundação de seu convento, da sé de Lisboa, expugnação dela, perda del-rei Sebastião... [Lisboa, Matheus Pinheiro, 1629], Lisboa, Imprensa Nacional-Casa da Moeda, 1867, ed. facsímil, 1993, pág. 155). Sobre los viajes del rey en estos años debe verse Joaquim Veríssimo Serrão, Itinerários de el-rei D. Sebastião (1568-1578), Lisboa, Academia Portuguesa da História, 1987. Para el contexto histórico en general, la bibliografía es abundantísima, pero sigue siendo imprescidible Queirós Velloso, D. Sebastião, Lisboa, Empresa Nacional de Publicidade, 1935 (reeditado, traducido al español e imitado en numerosas ocasiones).

${ }^{3}$ Sabido es desde Faria e Sousa que el relato camoniano del mito de Acteón (Lusiadas, IX, 26) oculta alusiones a los ministros del rey, comparados a perros que se han de comer a su amo. 
Por otra parte, no hay alusión al intento (o vana amenaza) de la reina Doña Catalina de retirarse a Castilla ante los desprecios y abandono de que la hacía objeto su nieto el rey, asunto que armó un gran revuelo en la opinión pública portuguesa y en la diplomacia europea a principios de 1571. Ello hace pensar que los poemas son anteriores, de 1570, o posteriores, de 1572, cuando el amago de fuga de la reina se recordaría ya como un episodio pasado. Tampoco hay referencias a la escapada que el rey hizo a Tánger en verano de 1574, asunto de suficiente importancia como para que éste sea considerado terminus ad quem (como hace Roiz Soares) de los poemas. Son admisibles, por tanto, las fechas que dan el Cancionero de Madrid y Barbosa Machado para el primero y tercero Avisos: octubre de 1572 y cuaresma de 1573.

De ser así, el segundo Aviso de la serie es probablemente cuatro años posterior al tercero, pues le preocupan otros asuntos: el tema central sigue siendo la política del rey, pero con unos contornos más concretos que el generalizado y a veces vago desgobierno denunciado en los otros versos. Aquí no se habla ya de los deseos de invadir tierras ajenas, sino de los planes para la jornada de África, y de los malos consejeros que la recomiendan pero que cuando llegue la hora se van a quedar a salvo en Portugal. Se le recuerda al rey que hace falta dinero, se le critica muy concretamente el propósito de ir en persona, cuestión palpitante en 1577, y se airean de nuevo las dos preocupaciones máximas del reinado: la salud del rey y su necesidad de tener sucesión, temas enlazados en la alusión final, bastante franca, a su supuesta impotencia. En cambio, ya no se

Véase además Américo da Costa Ramalho, «O mito de Actéon», Humanitas, 19-20, 1968, págs. 51-72 (recogido en Estudos Camonianos, Lisboa, Instituto Nacional de Investigação Científica, 1980), y Erilde Melillo Reali, «Atteone e il Re», Quaderni di Romanica Vulgaria, 2, 1980, págs. 47-62. La presencia aquí de lobos en el mismo contexto puede ser una radicalización de la misma imagen.

La carta a Luis Gonçalvez da Câmara será próximamente publicada en mi edición de la Miscelânea Pereira de Foyos, Lisboa, Imprensa Nacional Casa da Moeda, 2008, núm. 235. Su atribución a Jerónimo Osório viene de antiguo, empezando por la propia Miscelânea... (15721577), uno de los testimonios para el primer Aviso, y se mantiene en las dos ediciones de sus Cartas Portuguesas: la de Veríssimo Álvares da Silva, París, P. N. Rougeron, 1819, y la Nova edição, Coimbra, Universidade, 1922; núm. III. Queirós Velloso, sin embargo, piensa que su autor seria «algum partidário da Rainha, talvez de Pedro de Alcáçova Carneiro, a cujo afastamento do poder e substituição por Martim Gonçalves ela se refere» (José Maria de Queirós Velloso, op.cit., pág. 138). A. Guimarães Pinto, editor de las cartas latinas del obispo de Silves, más prudente, aduce argumentos en ambas direcciones: además de la tradición manuscrita, «o próprio modo expositivo, o sabor sentencioso do estilo, o entranhado sentido de imperativo cívico que percorre toda a carta, são outros tantos argumentos em favor da autoria osoriana», mientras que «o recurso ao anonimato —indício de tibieza pouco compaginável com os traços simples, mas vigorosamente vincados da personalidade de Jerónimo Osório-, bem como a notória má-vontade em relação à Companhia de Jesús...» serían argumentos contrarios a la atribución (Cartas, Trad. e notas de A. Guimarães Pinto, Câmara Municipal de Silves, 1995, págs. 140-141). 
alude a los Cámaras, aspecto fundamental para la cronología, pues el padre Luis había muerto en verano de 1575, y tanto su hermano Martim como Martinho Pereira, el tercer poderoso ministro, habían sido alejados del poder antes de un año. Librado de los validos viejos, don Sebastián se dejaba ahora dominar por otros, esta vez jóvenes y ambiciosos: Miguel de Mora, Cristóbal de Távora, Luis da Silva y Manuel Pereira Barreto, quienes, sólo por adularle, le aplaudían sus planes de invasión de África, por más informes e impracticables que fueran: «En ires todos conciertan,/ y en cómo ninguno acierta». Todo esto apunta a 1577, fecha confirmada por el protagonismo que adquiere el cardenal D. Henrique, «el abad de nuestra aldea», quien en el primer Aviso no aparece, y en el tercero es objeto apenas de una alusión pasajera. En el segundo, en cambio, también a él se le acusa de que «cuando tuvo la estación», es decir, durante su regencia (1562-68) consiguió enemistar al rey con su pueblo; ahora no opina sobre la jornada de África, pero aprovecha hipócritamente la situación en provecho propio y se prepara de diversos modos para substituir al rey si éste sale del reino para dirigirla en persona. El Cardenal, dicen las trovas, se finge viejo y achacoso, pero oculta con su silencio su ambición de verse coronado, que puede alcanzar ya sea suplantando a D. Sebastián en su ausencia o heredándole a su muerte; para ello ha puesto en movimiento a sus servidores, que andan averiguando las posibilidades jurídicas de que un clérigo sea rey. Esta denuncia sólo puede ser posterior al fallecimiento, en marzo y octubre de 1576 respectivamente, de la infanta Doña María, hija de D. Manuel, y de D. Duarte, duque de Guimarães, nieto del mismo; en la línea sucesoria de D. Sebastián ambos precedían a su tío el Cardenal, ahora heredero indiscutible a la corona.

La enemiga contra el Cardenal permite atribuir este segundo Aviso a alguien del partido de su cuñada y rival, la reina Doña Catalina, abuela del rey y desde 1569 muy apartada del gobierno por su nieto. Lo mismo no se puede decir de los otros dos, puesto que en ellos se alude en varias ocasiones a Felipe II como una amenaza para el reino, lo cual es incompatible con la posición política de la reina, devota de su sobrino español y en todo concorde con su política. Poco más se puede decir con firmeza sobre su autoría. João Franco Barreto, que copia los dos primeros y los dos últimos versos de la serie, y Barbosa Machado, que incluye la primera estrofa de cada poema, atribuyen la serie completa a D. Francisco de Portugal, nieto del homónimo primer conde de Vimioso, que fue poeta del Cancioneiro Geral. Este segundo D. Francisco, del Consejo de Estado de D. Sebastián, quedó cautivo en Alcazarquivir y, liberado en 1579, no llegaría a suceder en el condado a su padre D. Afonso, muerto en la batalla, por haber tomado el partido del Prior de Crato, que lo hizo su condestable; murió en la toma de las Azores por los españoles en 1582. Es posible que Barbosa 
Machado tuviese una fuente de información desconocida en nuestros días, pues sólo encuentro un detalle en que podría fundamentarse, pero débilmente, esta atribución: el pseudónimo Franco que en los títulos de tres de los testimonios ( $T, U$ y $M$, los más relacionados entre sí), así como en el cuerpo del tercer Aviso, se le da a la voz poética ${ }^{4}$.

La Miscelânea de Gil Nunes de Leão $(L)$, el testimonio más tardío (c. 163040), atribuye el primer Aviso a D. Manuel de Portugal, hijo del primer conde de Vimioso y, por tanto, tío de D. Francisco de Portugal. No hay ningún argumento a favor y sí varios en contra de esta atribución: importa sobre todo que la Miscelânea Pereira de Foyos, que por su fecha (fue compilada entre 1572 y 1577) es el testimonio más cercano al original, trae el mismo Primer Aviso como de «autor incerto», a pesar de ser una de las fuentes que con más abundancia nos ha conservado la poesía profana de D. Manuel de Portugal, incluyendo entre ella varios poemas de atribución dudosa. Don Manuel, además, no es poeta satírico, sino lírico y religioso ${ }^{5}$. Hay que pensar que Nunes de Leão actúa por su cuenta al substituir el nombre de D. Francisco de Portugal, que andaría en la tradición, por el de su tío D. Manuel, como poeta más famoso.

Por último, el Cancionero de Madrid, en una nota marginal, pero contemporánea, al Aviso segundo, junto al nombre Franco le identifica como «Francisco Aldana», atribución difícil de demostrar, pero no descabellada (por otra parte, la nota no le atribuye necesariamente la autoría, sino que se limita a identificar este consejero ficticio con el poeta español). Entre julio y octubre de 1576, Francisco de Aldana, como miembro prominente de la clientela del duque de Alba, estuvo muy probablemente en estrecho contacto en Madrid con el lucido séquito de Pero de Alcáçova Carneiro, aludido en el primer Aviso (68-72) como una de las víctimas de la política real. En efecto, el fiel servidor de D. João III y de Doña Catalina había sido apartado de la corte por sus desavenencias con los Cámaras; rehabilitado en cuanto éstos desaparecieron, estuvo en Madrid tres meses como embajador extraordinario de D. Sebastián ante Felipe II, y desde luego no era de los que aprobaban la Jornada de África. El Rey Prudente le asignó al duque de Alba como interlocutor directo, intermediario y huésped. Al-

\footnotetext{
4 João Franco Barreto, Bibliotheca lusitana. Autores portugueses. Ms. Casa dos Duques do Cadaval. Ejemplar fotocopiado en la Biblioteca Nacional de Lisboa, III, pág. 480; Barbosa Machado, loc. cit. Sobre la base de la autoridad de Barbosa Machado, la autoría de D. Francisco de Portugal es aceptada por Arthur L. Askins, ed. Cancioneiro de Cortes y de Magnates, Berkeley, Los Angeles, London, University of California Press, 1968, pág. 565). Nadie más, que sepamos, ha tratado el problema. $M$ le llama Fausto en el título del Aviso primero.

5 En la única edición existente de su poesías profanas, no encuentro un sólo poema satírico (Luís Fernando de Sá Fardilha, ed. Poesia de D. Manoel de Portugal: I. Prophana, Porto, Instituto de Cultura Portuguesa, Faculdade de Letras do Porto, 1991).
} 
dana, tras esta muy posible primera toma de contacto con la política portuguesa (y con la poesía de uso político, pues no olvidemos que con el embajador viajó Diogo Bernardes y quizá Jerónimo de Corte Real, ambos poetas muy destacados en este campo), fue enviado a espiar las fortificaciones y la presencia otomana en Marruecos, y en seguida a Lisboa (verano de 1577), con el encargo de disuadir a D. Sebastián de la invasión, exactamente lo que se hace en este Aviso, que se ajusta con precisión al punto de vista filipino sobre la inminente Jornada de África: no llevarla a efecto, y si se lleva, que no vaya el Rey a dirigirla en persona. Esta intensa relación de Aldana con la política portuguesa en los últimos años de su vida, sabiendo además que los tres Avisos no pueden ser del mismo autor (pues de ser así formarían una secuencia, y no es el caso) permite avanzar la atribución del segundo Aviso en el sentido del Cancionero de Madrid, si bien no de forma definitiva: el Divino capitán, que escribió en su corta vida abundante poesía política y de circunstancias, estaría ahora escribiendo en imitación del primer Aviso (el más difundido), que, como el tercero, sería de un poeta portugués, quizá el mismo D. Francisco de Portugal ${ }^{6}$.

\footnotetext{
${ }^{6}$ Justo García Soriano descarta la atribución sobre la base de que Aldana no sólo no logró disuadir a D. Sebastián, sino que parece haberse dejado impresionar por su personalidad y hasta por su proyecto («Una antología hispano-lusitana del siglo XVI», Boletín de la Real Academia Española, XII, 1925, págs. 360-375 y 518-543.1925). Hay que tener en cuenta que García Soriano escribe mucho antes de que los estudios y ediciones de E. Rivers iniciasen los todavía escasos estudios aldanescos. Hoy sabemos que en la personalidad y actividades del poeta hay amplios márgenes para la interpretación. Sobre este aspecto concreto de las contradicciones de Aldana, véase Elias Rivers, Francisco de Aldana, el divino capitán, Badajoz, Diputación Provincial, 1955; José Lara Garrido, «Introducción» a su edición de Francisco de Aldana, Poesías castellanas completas, Madrid, Cátedra, 1985, y José Miguel Martínez Torrejón, «Aldana, sus reyes y los retóricos turcos», Mélanges María Soledad Carrasco Urgoiti, Abdeljelil Temimi, ed., Zaghouan (Túnez), Fondation Temimi pour la Recherche Scientifique et 1'Information, 1999, págs. 437-462. Sobre los contactos de Aldana con la política y literatura portuguesa puede verse también Martínez Torrejón, «Ánimo, valor y miedo. Don Sebastián, Corterreal y Aldana ante la invasión de Marruecos», Península (Porto), 2, 2005, págs. 159-170. Existe además otra posibilidad no probada pero verosímil: Aldana, que se había pasado el año 1576 en Madrid haciendo avanzar su candidatura a la capitanía del castillo de San Sebastián, recurriendo a la influencia de su protector el duque de Alba, no sólo conocería a través de éste a los portugueses que integraban la embajada extraordinaria a Madrid, sino que además debió ir en Navidad de ese año, siempre con el duque, a las vistas que D. Sebastián y Felipe II celebraron en el monasterio de Guadalupe, donde tendría nueva ocasión de tratar con numerosos miembros del séquito del rey, entre ellos poetas como Diogo Bernardes y desde luego miembros de la corte opuestos a la «Jornada de Africa».
} 


\section{TEXTO}

Se han conservado al menos siete testimonios de estos poemas, aunque sólo tres $(T, U, M)$ contienen la serie completa:

$T$ Lisboa, Arquivo Nacional Torre do Tombo. Ms. Livraria 1112, códice facticio, fols. 462r-464r, 464v-465v, 466r-469r.

Final del s. XVI (papel de 1580-1590). Contiene la serie completa.

$U$ Lisboa Arquivo Nacional Torre do Tombo. Ms. Livraria 1112, códice facticio, fols. 470r-472r, 472v-475r, 475r-476v.

Final del s. XVI (papel de 1570-1580). Contiene la serie completa.

$F$ Lisboa, Biblioteca Nacional, COD 8920. fols. 126r-130v. Miscelânea Pereira de Foyos. Compilada entre 1572-1577. Contiene sólo el Aviso primero ${ }^{7}$.

E Évora, Biblioteca Pública Municipal, COD xiv/2-2, fols. 146r-148v.

Copia del anterior. Principios del siglo XVII. Contiene el Aviso primero. Codex descriptus de $F$, por lo que no se incluye en la colación ${ }^{8}$.

$M$ Madrid, Real Academia de la Historia, Ms. 9-24-5807-2. fols. 81r-102v. Cancionero Hispano-portugués de Madrid.

Finales del siglo XVI o principios del XVII. Contiene la serie completa $^{9}$.

L Lisboa, Biblioteca Nacional, COD 3563, fols. 167-170; 92r-93v.

Gil Nunes de Leão, Miscelânea.

C. 1630-40. Primer y segundo Avisos, en orden inverso y totalmente separados, como si fueran independientes.

$S$ Lisboa, Biblioteca Nacional, COD 938, fols. 41-45.

Pedro Roiz Soares, Memorial que contém todos os casos dinos de memória acontecidos nesta insigne cidade de Lisboa, cabeça prima das Espanhas...começados desd'a era de mil e quinientos e sesenta e cinco por diante...

Posterior a 1628. Contiene el primer Aviso ${ }^{10}$.

Hecha la colación de estos manuscritos, no se puede establecer con firmeza un stemma codicum, pero parece claro que hubo otras copias y que $T$ debe servir de texto base, como codex optimus y vetustissimus de la serie completa. Todos los demás presentan lecturas claramente erróneas, en varias ocasiones comunes, además de las numerosas lecturas comunes en variantes equipolentes,

\footnotetext{
7 José Miguel Martínez Torrejón, «Secretos a voces en un códice secreto: la Miscelánea Pereira de Foyos y sus ocultos motivos», Leituras. Revista da Biblioteca Nacional, Lisboa, 8, 2001, págs. 164-166.

${ }^{8}$ Publicado por A. Askins, op. cit. como Cancionero de Corte y Magnates. Vid. António A. Cirurgião, e Gordon Jensen, «Poesia peninsular do século XVI: o seu a seu dono», Biblos, XLVII, 1973, págs. 3-30.

9 Justo García Soriano, art. cit.

${ }^{10}$ Pedro Roiz Soares, Memorial... Leitura e revisão de M. Lopes de Almeida. Coimbra, Universidade, 1953.
} 
que hacen pensar en una tradición más compleja de lo que se puede reconstruir a partir de los testimonios conservados.

Modernizo la puntuación, acentuación, uso de mayúsculas y separación de palabras, así como el uso de consonantes dobles, semivocales y $h$.

Respeto las aglutinaciones vocálicas, el timbre de las vocales, y no sigo la práctica, común al editar textos del siglo XVI, de modernizar la ortografía de las sibilantes, porque en este caso puede haber correspondencia de los trueques (s/ss/z/ç; x/j/g) con la pronunciación portuguesa del autor.

\section{Primeiro aviso de Franco a su hermano Sebasto ${ }^{11}$}

Pide a tu juizio cüenta, zagal de ti descuidado, que se te pierde el ganado y piensas que se acrecienta. Traes cercados de engaños la vida, el seso y los años, de sueños y de locuras. Perderás, si no lo curas, tu poder y tus rebaños.

Las ovejas que solían ser de su amo regaladas andan tan amedrontadas que de verte se desvían por desiertos y montañas, como fieras alimañas: unas de otras divididas, se van huyendo esparzidas de las antigas cabañas.

En la tormenta más brava, cuando otros amos había, si el pastor que las regía

11 El primero de estos Avisos se conserva en todos los manuscritos: $T, U, F, M, E, L, S$.

10-36 Con otros amos (20) se alude al reinado de D. Juan III, idealizado en tiempos de D. Sebastián como padre y pastor de un rebaño feliz. Los corderos son los nobles, que evitan su presencia y no vienen a la corte, por lo que los más jóvenes, nuevos corderos, privados de este marco de referencia, andan desorientados. con un silbo las llamaba, iban corriendo a manadas por sierras deshabitadas, tan puestas en su querer que trocaran por le ver el abrigo y las majadas.

Agora sólo la sombra de tu nombre las destierra, dexan la vida y la sierra si alguno entr' ellas te nombra. Andan los nuevos corderos perdidos por los oteros,

y en tal odio se han criado que por huir tu cayado

buscan los despeñaderos.

Los conduzidos pastores que por rigirlos envías, con cruieldad y osadías levantan nuevos clamores. Unos mandas a contarlos, y otros a trasquilarlos.

37-45 Conducidos pastores son los ministros de D. Sebastián, dedicados sólo a censar y esquilmar a los corderos, que por eso no quieren saber del rey. El más cercano censo llevado a cabo en Portugal es muy anterior al periodo que nos ocupa, pues lo llevó a cabo D. João III en la década de 1530. La referencia puede ser a un censo parcial, regional, inconcluso o simplemente planeado, al que también parecen aludir los vv. 132-135. 
Y después de hurtada la lana de tu vida no habrán gana, si ansí quisieres tratarlos.

La sierra el pasto les niega, el cielo esconde el rocío, el agua perturba el río y con ella el fruito anega; el aire amenaza muerte, y en todo es mala la suerte, el tiempo, duro inimigo; siendo tú solo su abrigo, ni las ves ni pueden verte.

Como salvage inhumano

solo por los montes andas, la flaca caça demandas y das al ocio la mano. Dexaste todo el cuidado de tu humilde ganado a fieros lobos hambrientos, que a su crueldad atentos en su sangre se han cebado.

\section{Estos te dan la razón} del tiempo y de las ovejas, y pues tú les das orejas, ellas bien perdidas son.

46-54 Referencia a los malos tiempos sufridos por el pueblo en los primeros años de D. Sebastián: malas cosechas, sequía, inundaciones, y muy especialmente la gran peste de 1569, origen del excesivo abandono de Lisboa por parte del rey, que debería ser protector de su ganado y sin embargo se había hecho invisible al mismo.

55-63 El rey, como un salvaje, está solo, separado de su rebaño, y se dedica a la caza dejando a los suyos en manos de lobos hambrientos, imagen que podría estar emparentada con la de los perros que sin duda rodean al cazador y que, como a Acteón en Os Lusiadas, acabarán comiéndoselo. La carta de Fr. Jerónimo de Osório a Luis Gonçalves da Câmara, mencionada en la introducción, ilumina este pasaje al llamar a D. Sebastián montesinho, en sentido bisémico: dedicado a la caza por el monte, y tambien «ferino», criado sin padres,
Luego de ti apartaron

los mastines que guardaron siempre tus ricas manadas, por lo cual son derramadas y tu compañía dexaron.

De ti señores se han hecho, miedo estraño dellos tienes, estragan todos tus bienes y quedas muy satisfecho. Como animales bravosos de toda cosa ambiciosos, ninguna a su sabor dexan, y los tristes que se quexan prueban sus dientes rabiosos.

Los montes desasosiegan haziendo por las aldeas tocar arma, y sus peleas el ageno sangre entregan. ¿Cómo no ves, descuidado, cuánto todo se ha mudado, estragado y destruido, y en cuán poco se ha perdido tu nombre tan estimado?

Los términos que estendieron esos antigos pastores

sólo. Ambos sentidos parecen encontrar eco en este Aviso.

64 dan la razón: dan cuenta de su estado.

68-72 Hay una posible referencia concreta al caso de Pero de Alcâçova Carneiro, el más notable de sus antiguos mastines (buenos ministros) durante la infancia del rey. El viejo servidor de la corona se retiró de la corte en 1570 debido a desavenencias con Martim Gonçalves da Câmara. En general, se alude a la vieja guardia de los tutores y gobernadores del rey durante su infancia, incluyendo a su abuela Doña Catalina y su tío abuelo Don Henrique.

84-85 peleas, como el antiguo «batallas», vale aquí 'ejército': 'Los ejércitos derraman (entregan) sangre ajena'.

91-99 Con esta pérdida de terrenos, tomados por los vecinos, difícilmente se alude a Castilla, sino más probablemente a la India o 
en tu tiempo son menores, y los vesinos crecieron. Los zagales comarcanos, si vinieren a las manos, no hallaran resistencia, pues no saben tu presencia los tuyos a ti cercanos.

No dexas dellos tratarte, 100 cada uno de sí se absenta y tiénente en otra cuenta del que eres en toda parte, porque es tu naturaleza aficionada a grandeza, y son muy baxas tus obras.

En clemencia a todos sobras usas siempre con crueza.

Mucho amas la verdad y ninguno en ti se fía, no hazes justicia un día $\mathrm{y}$ pregonas igualdad. Quieres que todo el poblado te tenga por esforçado, y no osas a mandar. Quiéreste pastor nombrar y de otros eres criado.

Liberalidad estimas, y pides y hurtas lo ageno; crees que ser amado es bueno y a todos la alma lastimas; a Marruecos, ambos territorios extendidos hasta tiempos de D. Manuel, y donde se habían perdido posiciones recientemente. Desde luego, está la presencia de España como amenaza: los zagales comarcanos, nos vencerían, pues tus súbditos no saben dónde estás (entendido el rey como protector de su rebaño).

100 De nuevo la ausencia de los súbditos y la soledad del rey intratable, tema que esta vez lleva a las contradicciones de su persona: aparenta grandeza y obra lo bajo. Presume de clemente y es cruel, etc. La serie redunda en la misma idea del mal gobierno en general, pero importan sobre todo dos contradicciones: fingir ser rey y ser criado de otro, alusión cla- luchas, corres, y hazes galas,

y aborreces las zagalas,

y en todo te contradizes:

si de ti no te desdizes

guárdete Dios de horas malas.

Quieres seguir lo pasado, lo presente se perdía,

mueres por la compañía

$\mathrm{y}$ andas desacompañado

para las cosas que atiendes.

Cuántas son saber pretiendes tus ovejas de un montón, y no sabes cuáles son: ni lo entiendes ni te entiendes.

Diziendo que es igualdad, van las buenas con las malas, y cuando ansí las igualas ¡qué mayor desigualdad! Quieres ser dellas temido, y házeste aborrecido, flaco y desestimado. Quedarás león llamado entre ganado rendido.

Eres sobre todos cuerdo y hazes dos mil locuras. Cuando acertar más procuras sigues el camino esquierdo. De la razón te agenas, y temo, según te ordenas,

ra a su valido, y hacer galanías de joven, siendo así que aborrece las mujeres.

127-135 Seguir lo pasado es volver a lo que se perdió en África, descuidando lo presente (el gobierno de la nación) en el proceso. De nuevo se alude al censo no identificado de los vv. 37-45. D. Sebastián manda contar a sus súbditos (para extraerles impuestos) sin conocerlos. La falta de compañía reaparece como causa y consecuencia de este proceder.

129 Mueres por la compañía: se juega con el doble sentido entre «desear tener compañía» y «morir por culpa de la Compañía (de Jesús)», en nueva alusión al jesuíta Luís Gonçalves da Câmara. 
que avisado tarde quedes.

Tus tierras guardar no puedes, quieres ganar las agenas.

Con sus soberbios cayados los vezinos te demandan, y los tuyos tales andan que se darán de sus grados. Perdieron ya todo el brío después que su señorío a los mercenarios diste, y pues los aborreciste, que te aborrescan yo fío.

Todo ordenas al revés de lo que es razón que ordenes, a unos mal, a otros bienes y a nadie lo para ques. ¿No ves que engaño sería hazer de un ciego tu guía y sobre un coxo firmarte y con aquel aconsejarte que experiencia no había?

¿Qué fuera si a un doctor entregases el rebaño? Cierto fuera igual engaño haber libros un pastor. $\mathrm{Si}$ las ropas coloradas del sangre de tus manadas a un jornalero viesses,

154 Los soberbos cayados del vecino amenazan, pero la amenzaza es siempre interior: el propio rey que entrega su poder a los mercenarios y aborrece a sus súbditos, que se pasan al vecino. No puede tratarse más que de Castilla, quizá aludiendo a un caso concreto de un súbdito tránsfuga.

167 Probablemente la alusión más directa a los tres que acaparaban hasta 1575 la voluntad del rey: su confesor, el ciego Luis Gonçálves da Câmara, su hermano Martim, escrivão da puridade, probablemente cojo, y Martinho Pereira, veedor da fazenda, que no tenía ninguna experiencia de gobierno y cuyo único mérito era oponerse al matrimonio del rey.

177 del sangre: el género masculino es lusitanismo (o sangue). ¿qué fuera si las quisieses

fiar dél otras vegadas?

180

Si hallases dos zagales

enemigos del ganado

que todo hubiesen dañado,

locos, feos, desiguales,

y que con sus lenguas sueltas

te metiesen en revueltas

con vezinos y estrangeros

por hazer los compañeros,

¿qué fuera dar muchas vueltas?

¡Cierto locura sería,

190

que hasta el bruto animal,

si una piedra le haze mal,

de pisarla se desvía!

Al gobierno el pastor venga,

con el lobo el can se avenga,

y el zagal corra ligero,

la yerba guste el cordero:

cada uno su lugar tenga,

porque cada uno demanda

diferente inclinación,

200

y quien trueca la razón

por sinrazones se manda.

Tú de manera mudaste

en la vida, que tomaste

lo que a cada cual debías,

205

que no pasarás los días

sin emienda o sin contraste.

181: los dos zagales pueden ser los mismos hermanos Cámara o Cristóbal de Távora y Luis da Silva, sus dos favoritos jóvenes. Estos son quienes embarcan al rey en aventuras extranjeras por hacer los compañeros, es decir, por cultivar la misma camaradería juvenil con que se iban de caza; se van ahora a Tánger, sin motivación político-militar. dar muchas vueltas es pensarlo, dar oídos a lo que le aconsejan.

202 se manda: 'quien deja la razón se deja regir por la sinrazón', a menos que «mandarse» tenga un significado que se me escapa.

207 sin enmienda o sin contraste: 'si no cambias vas a tener siempre oposición (de tus súbditos)'. 
Mira que van tus ovejas gimiendo por las aldeas, y tú ni las remedeas ni les das pasto ni orejas. Bien ves que los comarcanos andan alegres y ufanos, sus límites ensanchando, los dulces ríos gustando, remotos y los cercanos.

Tienes edad y cordura y campos, aunque robados, tienes rebaños vezados a buena y mala ventura. Dexa el cochillo y cayado, y dexa lo que has aprendido, será tu sueño dormido

Y pues de todos te apartas, apártarte ahora de ti: verte has como te vi, que de vierte no te hartas. $\mathrm{Si}$ de lexos te mirares y bien te considerares, verás que tu descrición, verdad, seso y condición han dexado sus lugares.

Verás que se señorean, en pieles de tus corderos los lobos bravos y fieros, de cuanto de ti desean. Verás, si vierte quisieres, que te hazen menos amado y el reposo descansado.

cuan otro mudado eres

d'aquel que pudieras ser,

y llorarás de te ver

como yo de no te veres.

Donde, si hallares que siento verdad en mi presunción,

no quiero más galardón que este tu conocimiento, porque si das por desculpa que tienen otros la culpa del mal que tú mismo obras, quedan sin vigor tus obras y tu razón más te culpa.

Pide a tu juizio cuenta, reconoce tu ganado, verás que en todo ha menguado 255 y que el daño se acrecienta. $\mathrm{Y}$ si algún bien deseas yo te ruego que te creas, porque a la fe que no dañes, y aun mejor es que te engañes que no que engañado seas.

258 que te creas, es decir, que escuches lo que te dice tu juicio, tu conciencia, en lugar de seguir haciendo oídos sordos a cuanto sabes.

264-265 ganartel a quien te trae usurpa$d o$ : a diferencia de su significado moderno, no quiere decir 'conquistar la voluntad de...' sino 'imponerse a..., vencer'.
Tu dolencia te he mostrado: si deseas remediarte, debes procurar ganarte a quien te trae usurpado; $\mathrm{y}$, en suma, lo que deseo daqueste mi devaneo que he tomado en escrebirte es que quieras advertirte, porque en peligro te veo. 


\section{Segundo aviso de Franco a su amigo Sebasto ${ }^{12}$}

Dizen que piensas volver al mal que se recelaba, para que si algo quedaba se acabase de perder. Mas yo, como verdadero amigo y no lisongero, otra vez te he de avisar, puédeslo tan mal tomar como tomaste el primero.

Con zagales descontentos, pobres, ricos de pesares, ganarás, cuando ganares, tu locura y sus tormentos. Los pastores que han ganado ageno pasto y ganado sabes de qué suerte ha sido: con el suyo, tan querido como es de ti desamado.

Por solos tres pareceres que no valen cuanto uno,

$12 T, U, M, L$. Barbosa Machado (loc. cit.) afirma que este Segundo aviso tiene 14 estrofas: le falta, pues, una para completar los 135 versos que el poema tiene en las versiones TUM; reproduce la primera estrofa, idéntica a $M$, y lo atribuye, como el anterior, a D. Francisco de Portugal, con la siguiente explicación: «Segundo aviso de Franco a Sebasto, que se deu a el-rei D. Sebastião em Évora, a 24 de Dezembro de 1572». Al margen de $M$, un asterisco tras Franco remite a las palabras Francisco Aldana, en añadido posterior. Los 40 versos finales, aquí impresos entre paréntesis cuadrados, sólo están presentes en el manuscrito $L$. Son un añadido de muy distinto momento y autor, quiza del mismo Nunes de Leão, imitando el contenido del primer Aviso sin notar el contrasentido que introduce en el segundo.

1 No hay por qué tomar volver como referido a un regreso a África, donde ya habría estado. Aquí puede ser simplemente volver al tema, a la insistencia en sus planes expedicionarios, por vagos que fueran. aventuras de consuno nuestra vida y tus poderes. Claro está ser desvarío querer perder lo que es mío solo por ganar lo ageno:

mete la mano en tu seno, contempla tu señorío.

Esto bastara y no más se viesses como pareja, que el que a guerra te aconseja, 30 es cierto quedar atrás.

$\mathrm{Y}$ aunque todo lo tuviesses y más de guerra supiesses, cometerlo era gran vicio, pues tu edad al exercicio no basta, por más que hiziesses.

El abad de nuestra aldea, si no habla, bien se calla; juro a diez que pienso halla camino a lo que desea.

5-9 La referencia a unos Avisos anteriores no indica necesariamente la misma autoría, sino el carácter de continuidad que aquí se asume.

14-18 Se le reprocha el no tener el favor de sus súbditos, indispensable para las conquistas que pretende emprender.

17 con el suyo: 'con su pasto', es decir, cuando los pastores ganan terreno ajeno es a costa de perder (o arriesgar) el propio.

25-26 mete la mano en tu seno es 'conócete, obsérvate a ti mismo'; aunque aquí se le ha dado a la rima otro sentido, en el refranero hay varias versiones de rima ajeno/seno: « $\mathrm{Al}$ juzgar un hecho ajeno, mete la mano en tu seno», es decir, "mírate a ti mismo antes de juzgar a los otros'.

34 cometerlo: acometerlo.

36 no basta: no resiste, no es suficientemente fuerte para acometer, emprender, el nuevo deporte.

37 Comienzan las alusiones a la actitud engañosa del cardenal D. Henrique, que separan radicalmente este poema del anterior. 
Después que echó bendición, cuando tuvo la estación tuvo de odio y malquerencia, y pegóte su dolencia por nuestra condenación.

Para todo lo que quiere, ¡oh cuántas de artes que sabe! En todo el mundo no cabe y pregona que se muere. Mas dél hogaño dizían los que las letras sabían que los suyos se informaban si los que missa cantaban regir y mandar podían.

Por esso mira, zagal, si esto es burla o burletas y primero que te metas ve salida al tremedal. Porque viéndote tornar sin lo que fuiste a buscar quizá harán dél mudado y si vinieres cansado no te darán el lugar.

En ires todos conciertan, y en cómo ninguno acierta, la verdad debe ser muerta, pues viven los que esto asiertan. Como los bienes verá

58 ve salida al tremedal: 'búscale salida al pantano'.

61 harán dél mudado: se refiere al lugar, mencionado en el v. 63, es decir, cambiarán el reino de manos, substituirán al pastor-rey que se va y regresa derrotado (D. Sebastián) por el abad que se queda temporalmente en su puesto (D. Henrique).

67 asiertan: asertan, afirman. El diptongo hipercorrecto, típico de los portugueses que escriben castellano, puede deberse al copista, pero hay que respetarlo por cuestión de principio.

77-81 Como en el caso anterior, los diptongos incorrectos (fundamiento, piensamiento) no afectan en realidad a las rimas, y pueden por tanto deberse al copista portugués. La frase de los dos últimos versos es extraña. Probablemente se trata de una paradoja un aquel que poco le da

del mal que pueda venir.

$\mathrm{Y}$ todo su prevenir

es cómo más mandará.

Mira tú, Sebasto amigo, cuán pocos años que tienes, goza primero los bienes que el mal que te ahora digo. $\mathrm{Tu}$ ánimo y fundamiento son llenos de grande intento, mas hablando la verdad tanto mengua en tu edad cuanto sobra el piensamiento.

Cuál es lo mejor sabrás, mas el cómo se ha de hacer no lo puedes aun saber: ¡cuán mal que lo enseñarás! Y porque me halles razón mira mismo la elección que hasta aora tienes hecho: de los que en su proprio lecho no sueñan ser lo que son.

Como bien que no esperaban y que vino por ventura, usan dél con tal soltura que hacen rir los que lloraban. No contentos con el suelo, toman la alçada del cielo

poco forzada: en tu edad el pensamiento es tan escaso como sobrante, es decir, es escaso porque todavía no se ha desarrollado y sobra porque a los jóvenes les parece innecesario pensar, prefiriendo aplicar el ánimo.

82-85 Es fácil saber si conviene o no realizar la expedición. Lo que no sabes es cómo, con qué medios, etc. Es la perspectiva usada a lo largo de todo este Aviso: no importa la justicia de la invasión, sino su viabilidad.

86-90 Quienes no sueñan ser lo que son son los validos, encumbrados por el rey de forma inmerecida e inesperada, de donde viene su carácter abusivo comentado seguidamente.

96 Toman la alçada del cielo: le toman la medida, alcanzan el cielo con la mano. 
y al sabor del paladar

lo van a abrir o cerrar

mostrándote muy gran celo.

Mas ya que nuestra malicia

100

pasa el punto de piedad,

usa la suma bondad

con gran razón de justicia.

Cayo, Nerón y Antonino

$\mathrm{y}$ un hombre que ahora vino

105

han sido ministros desto,

y bien nos muestra en su gesto

su corazón y camino.

Los cristianos y los moros cuando quieren conquistar cierto está que han de ajuntar primero grandes tesoros.

Tú desto pierde cuidado y procura ser amado,

pues no tienes más que dar

que con blandura tratar al pueblo tan mal tratado.

Mira bien por tu salud antes que naturaleza

se vea en tanta flaqueza

que rienda el mal la virtud.

Sano, recio y en edad buena

sigue lo que el fado ordena, y no te enfades en esto,

que, muchacho y mal dispuesto, 125

no lo harás sin grande pena

Del abad de que te hablé pienso de escrevir tres cosas, que son las más espantosas que en toda mi vida hallé: humos de rey soberano que todo tiene en su mano; y de lo que más me espanto:

118-126 Franca alusión a la impotencia del rey: sigue lo que el fado ordena, es decir, hace lo propio de su edad el que está sano, recio y en edad buena, mientras que a ti, muchacho (demasiado joven) y mal dispuesto (enfermizo) te va a costar esfuerzo y disgusto. las apariencias de santo

y las temas de villano.

135

[Mira, pastor, do te envían,

mira bien para dó vas,

cuando cojos ciegos guían

¡ay de los que van detrás!

Mira que eres virtuoso,

no te lleven al desierto

quedando el ganado muerto, que nunca tendrá reposo.

De todo el bien te desvían, huye del lobo roaz,

que cuando los ciegos guían

¡ay de los que van detrás!

Tu ganado, con la roña,

no tiene leche que dar,

si lo quieres ordeñar,

no es leche, mas es ponzoña.

Para roazes se crían, mira pastor y verás, cuando ciegos cojos guían, ¡ay de los que van detrás!

No te engañe hipocresía, no vivas della engañado, antes le arroja el cayado, vaya vivir do solía.

$\mathrm{Si}$ no ves quien te desvía, pergunta, saberlo has, que los ciegos que te guían vante robando asaz.

No pienses que son leales los que traes capuchados, engañan como engañados, sus engaños son caudales. Mira bien dó te envían, abre los ojos, verás que son cojos los que guían y sanos quedan atrás.]

135 temas: frase o actitud repetida innecesariamente. Aquí, manía, testarudez, propia de villano, frente al entendimiento o espiritualidad esperables de un cardenal. 


\section{Aviso tercero ${ }^{13}$}

Di, pastor, ¿tú por ventura duermes, di, o estás despierto? $\mathrm{Si}$ duermes, es desconcierto, si no duermes, es locura. Muda, muda ya el pellejo, no deseches el consejo de tu buen amigo Franco, que de verte errar el blanco se le hace el rostro bermejo.

Otro aviso darte quiero porque soy amigo sano, querrá Dios no sea en vano como lo ha sido el primero, porque vejo tu ganado perdido y descarriado, y tú desto tan ageno que quien le ha dado el veneno piensas tú que le ha sanado.

Mira, pastor, que es engaño trasquilar contra derecho, y querer hazer provecho a costa de ageno daño, que aunque este provecho tal no te causase otro mal, sino hazerte aborrecible, ve si hay daño más terrible a tu oficio pastoral.

Mira a quién das tus orejas, si es fiel, si es verdadero, que el lobo es mal consejero en cosas de las ovejas, qu'este las que ha de tragar haze por las repastar; las demás hinche de roña

5 y la repasta emponzoña porque no puedan medrar.

De tu cayado el gobierno deseaban tus corderos, que en poder de jornaleros todo el año le era invierno, pero aquella malandanza que en tiempo de la esperanza era aunque grave, sufrible, Ahora es dura y terrible porque esperaban bonanza.

Esperaban de tu mano, como de pastor y amigo, en el invierno el abrigo, las sombras en el verano. Pero en tu temporada, porque se ve tu manada que anda al sol en el estío y en el invierno anda al frío, va a buscar otra majada.

Busca otro pasto y verduras, pensando que en todo el año no curarás del rebaño, pues de ti mismo no curas. Porque tan embelesado te muestras con el cuidado

60
13 Barbosa Machado, loc. cit., menciona este Terceiro aviso dado a el-rei D. Sebastião em Évora na Quaresma do anno de 1573, incluye la primera estrofa coincidiendo con la lectura de $U$ y atribuye el poema, en la secuencia de los anteriores, a D. Francisco de Portugal.

13 el primero: según fue comentado en la introducción, se refiere al primer Aviso de esta serie, mientras que el segundo no es conocido para el autor de este tercero.
33 repastar: pastorear, llevar a pastar.

35 repasta: pasto. $\mathrm{El}$ mal pastor procura que las ovejas que él se ha de comer pasten bien y engorden, mientras que a las otras les envenena los pastos para que no medren. El uso de la misma palabra como sustantivo y como verbo es lo que origina la lectura errónea comentada en el aparato crítico.

40 le: se refiere a tus corderos, aunque se ha hecho concordar con un 'ganado' sobreentendido. 
del vivir a tu sabor que de quien eras pastor

El ganado que tal anda 100 te dexaste hazer criado. si llora su malandança logo dél hinchen la panza,

Si al provecho, si al servicio de tu ganado no atiendes, dizen que el pastor lo manda.

mira que a ti mismo ofendes Mira, pues, si es buen derecho en dejar perder tu oficio, que el ganado, de no verte, empieza a desconocerte, aunque es tuyo y aunque es bueno,70 $y$ pensando que es ageno vendrá aun a aborrecerte.

Pues pastor, si algo te va a tu oficio y a tu rebaño, agradece el desengaño y abraça a quien te lo da. que andes tú muy satisfecho y desto que aquí te digo los odios queden contigo y con otros el provecho.

Y lo que es más lastimero es que hazen de ti tan bobo que te hazen juzgar por lobo al más chiquito cordero. Y para que sus gemidos Abre los ojos y orejas, oye y mira tus ovejas, oirás su desconsuelo, verás como andan sin pelo y de su sangre bermejas.

Podrás oír sus gemidos que no sé yo con qué maña van por toda la montaña y no van a tus oídos.

Podrás ver si fueres sano Que eres su pastor en vano, pues tus descuidos son tales que los tus mismos zagales las trasquilan con tu mano.

Y después de trasquilada a su sabor lana y cuero, quieren aun que el cordero pida otra lana prestada. El mal tiempo y el ventisco llevaron todo a barrisco de tu majada y ganado, pues siempre anda trasquilado, al granizo y al pedrisco. no te aviven los sentidos o te atupan las orejas, tristes gemidos de ovejas te dizen que son aullidos.

Con esto tus pensamientos andan tan llenos d'engaños que huyes de los rebaños como de lobos hambrientos, y si va a tu majada la ovejuela lastimada buscar tu amparo y abrigo, la tratas como enemigo y le arrojas tu cayada.

Los corderos de tu hato se mueren y desbaratan, que unos tus perros los matan, otros tu ceño y maltrato, siendo cada año menos y de roña todos llenos, por tu culpa nunca sana. Quieres vestir de su lana los tuyos y los ajenos.

Quizá piensas o lo viste, que tu hato a todo sobra,

115 atupan: del portugués atupir ('entupir, atascar'), aunque aquí con el significado de 'llenar, ocupar enteramente'. 
bien lo has visto por obra, que a ti solo apenas viste, porque cuando te ensanchaste y un sayo nuevo cortaste más ancho de que solías, acaballo aún no podías y hasta el hueso trasquilaste.

Si has por bien empleado 145 dar tu rebaño a leones por alargar los mojones de tu aprisco deseado, no sé, pastor, quién te engaña, y tú verás cuánto daña

en los tiempos venideros con sangre de los corderos ensanchares tu cabaña.

Si esta tan clara razón no entra en tu pensamiento, $o$ te falta entendimiento o te sobra la pasión, que si sordo no estuvieses imposible es que no oyeses tantos llantos, tanto ruego, y si no estuvieses ciego, que al medio dia no vieses.

Ojalá que aun vieras menos y que con tus ojos vieras, que en esto menos perdieras que en ver con ojos ajenos. $\mathrm{Ni}$ es mucho si devaneas, porque como tú no ojeas sino por donde ellos andan, ves sólo lo que ellos mandan y no lo que cumple veas.

\section{Y porque más del mesquino}

153 ensanchares: lusismo 'que ensanches'. 193 sus cayados: los poderes de los zagales-ministros, limitados en la aldea-Lisboa, motivo por el cual arrastran al rey por otros lugares. hato crescan los enojos, también son ciegos los ojos que te muestran el camino.

Ansí tú y tus corderos que por peñascos y oteros al ciego traes por guía, forçado será que un día des en los despeñaderos.

Mira, pues, que te conviene, pastor, voltear el cayado para librar tu ganado de quien por suyo lo tiene, porque según las señales que veo, $\tan$ poco vales que has llegado a estado tal que hoy en día eres zagal de los tus mismos zagales.

Tráente por despoblados adonde nadie te vea porque dentro en el aldea son más cortos sus cayados. $\mathrm{Y}$ por mas embelezarte hacen contino ordenarte luchas, bailes y otras galas, y al nombre de las zagalas hazen luego santiguarte.

Uno dicen que es derecho, y el otro dicen que es malo, pero uno es por su regalo y el otro por su provecho. Con las fiestas y invenciones regalan sus corazones,

y con huir de zagalas hacen buenas intenciones.

190-207 Se alude de nuevo al 'secuestro' del rey por parte de los hermanos Cámara, trabajando en su propio provecho, y a la responsabilidad de éstos en la soltería del rey: se les acusa de huir de las mujeres, intenciones malas que disfrazan de buenas intenciones, es decir, disfrazan la homosexualidad de casta santidad. 
Di qué mudanza es aquesta

tan contraria de tus años que tu comer y tus paños son de luto aun en la fiesta. $\mathrm{Si}$ es por honestidad, no te dicen la verdad, pues es claro y manifiesto que no puede ser honesto lo que es contra dignidad.

Ya yo te vi al día sancto y también por la semana, por no ser fina la lana, no querer cubrirte el manto y buscar nuevas labores y lanas de mil colores de que tus sayos hacías para ir a las compañías de zagales y pastores.

Tu hato entonces medraba y tus corderos crecían porque el placer que en ti vían más que el pasto les criaba. Agora cabescaídos andan, flacos y perdidos por te ver tal sobrecejo,

208-225 La severidad en el trato y ropas, tendencia de la corte portuguesa ya en tiempos de D. João III, se acentuó, en efecto, en tiempos de D. Sebastián, debido probablemente a la influencia del padre Luis. Aquí es visto como algo deshonesto por ir contra la dignidad real y por ser un medio más de apartar al joven rey de lo que corresponde a su edad: ir de fiesta y galantear entre jóvenes.

225 Por la rima y el sentido (andar de fiesta entre jóvenes de ambos sexos), no hay duda de que esta es la lectura correcta, presente en $U M$, en lugar de la enmienda introducida por nuestro texto base, T: zagalas y pastoras, que es visible excusatio non petita. En un texto que tantas veces alude a la homosexualidad del rey, a $T$ le ha parecido excesivo decir que en otro tiempo el rey anduvo en fiestas con jóvenes varones, pero ni el género masculino se refiere exclusivamente al sexo masculino ni andar de fiesta con pastores significa más que y aun por tu mal consejo no pascen sino gemidos.

Yo no sé d'ónde esto viene, 235 de ti o de tus zagales, pero sé que a tantos males darse remedio conviene. Venga d'onde quiera el daño, pues tuyo es todo, y el paño corta por do mejor fuere. Padesca quien padeciere, no padesca tu rebaño.

\section{$\mathrm{Y}$ aquel zagal de bermejo} no gane más tu soldada, porqueste en cada majada suele mudar el pellejo, $\mathrm{y}$ aqueste fue el primero que trasquiló lana y cuero. No sé si es cuerdo, si bobo, pues con corderos es lobo y con lobos es cordero.

Tu mal ya tienes oído, cumple a ti darle el remedio y si óllo era medio, harto tienes ya oído.

eso mismo. La enmienda misma es muy significativa como síntoma de la hipersensibilidad reinante en torno a la sexualidad de D. Sebastián.

235 d'ónde: 'de dónde', es lusismo repetido en 239. de onde («de donde»), relajado en d'onde, se identifica erróneamente con el castellano 'donde', creando cierta dificultad para la lectura, motivo por el cual lo edito con apóstrofe. Después de elaborar largamente sobre los responsables, se le pide al rey que se olvide del origen de la situación presente y corte por lo sano por el bien del pueblo.

244 zagal de bermejo: visible alusión al cardenal D. Henrique, a quien se acusa de hipócrita y de haber esquilmado al pueblo cuando fue regente (248-249). Aunque ahora está apartado del poder, puede ser recuperado para el mismo por el rey, a quien se le advierte que no lo haga. 
Yo, antes que me aparte, un aviso quiero darte que aun te dirá quien te engaña: que quien te avisa te daña, pero él quiere engañarte.

Y si tú con atención juzgares lo que te digo verás quién es tu amigo y quién lo es de su zurrón. Con esto sólo concluyo, que cuando tú fueres tuyo verás si te es más derecho quien te avisa en tu provecho o quien te avisa en el suyo.

Pouca força tem razões para emendar vontades e muita as adulações, onde não valem verdades.

\section{VARIANTES}

No se incluyen aquí unas pocas variantes claramente erróneas o meramente ortográficas, exclusivas de un testimonio enfrentado al resto de la tradición, como 114 tienga $F$ (= tenga), 201 troca $F$ (= trueca), 193 pisalla $F$ (= pisarla)

\section{Aviso primero}

Título Primeiro aviso de Franco a su hermano Sebasto $T$ : Aviso profético dado a el-rei Dom Sebastião de Portugal na era de 1572, no mes de outubro $M$ : Avisos em trovas dum autor incerto $F$ : Aviso de Franco a seu amigo Sebasto $U$ : Estas fez dom Manuel de Portugal a el-rei dom Sebastião antes que passara a Africa a primeira vez $L$

Fausto, pastor, a su amigo Sebasto $M$ : om TUFLS

4 se $F T M U$ : se te $S L$

5 cercados FTUL : cercado $M S$

8 lo $T U M S$ : te $F$ : le $L$

11 de su amo TUML: del su pastor $F$ : de tu amo $S$

12 amedrontadas $F T$ : amedrentadas $U M L S$

16 de otras FTMLS : y otras $U$

20 amos $T M$ : años FUSL

21 si FTULS : solo $M$

22 silbo TUML : silvio $S$ : silvillo $F$

25 puestas en TUS : puestas a $F L$ : prestas a $M$

26 trocaran $T U$ : trocaban $F M L S$

28 Agora solo TUMS : Ahora sola $F L$

30 vida y la sierra $T U$ : vida, la tierra $F$ : vida y la tierra $M L S$

31 entrellas TUMS : antre ellos $F$ : antrellas $L$

32 nuevos TFMLS : novos $U$

35 que por huir tu cayado TUM : que huyen de lo poblado $F$

36 buscan los despeñaderos TUMLS : y buscan despeñaderos $F$

259-261 El sentido (no entendido por $T U$, que enmiendan) es: te diré quien te engaña, pues quien te avisa (es decir, el poeta) te daña (te dicen cosas que duelen), pero él (el consejero que tienes: el padre Luis) te engaña. 
38 que por rigirlos $T L:$ que a regirlos $M:$ que pera regir $F:$ que a corregirlos $S:$ que por los contar $U$

39 y osadías TUMLS : los habías $F$

40 levantan TUMLS : y llevan $F$

41 unos mandas a contarlos TUMS : uno mandas a açotallas $F$ : unos mandas a contarlas $L$

42 y otros a trasquilarlos TUMS : y otros a trosquilarlas $L:$ y otro a trasquillarlas $F$

43 Y después de hurtada $T U$ : después de fuera $F$ : Después de hurtada $M L S$

45 tratarlos TUMS : tratarlas $L$ : tratallas $F$

46 sierra $T U$ : tierra FML : tierra y $S$ [La lectura tierra de FML parece mejor, como oposición a cielo, en el verso siguiente, con todo, mantengo la del texto base, pues su sentido también es correcto.

48 el agua $T U M:$ la lluvia $F$ : la agoa $L S$

49 anega $T M L S$ : niega $F$ : aniega $U$

51 y en todo $T U$ : en todo $F M L S$

52 el tiempo, duro y enemigo MLFSU : om $T$ les una de las pocas pruebas de que U no procede de $\mathrm{T}$.

52 duro inimigo $S U$ : duro y enemigo $M$ : crudo $F$ : dura inimigo $L$

55 salvage $T U L:$ selvage $M:$ salvagem $F S$

56 montes TFMLS : campos $U$

57 flaca TUFLS : triste $M$

58 ocio la UFS : ocio de $T$ : otro de ML [Sustituyo en este caso la lectura del texto base por ser la menos probable 'dar al ocio la mano' vale 'entregarse al ocio', mientras que 'dar al otro de mano' sería 'abandonar las otras cosas', olvidar las otras obligaciones en favor de la caza. La lectura intermedia de $\mathrm{T}$ tiene más difícil explicación.

62 que a su crueldad atentos $T U L$ : que su crueldad y intentos $F S:$ y sus crudeles intentos $M$

63 en su sangre se han cebado $T$ : en su sangre se han bañado $U$ : en la su sangre han cebado $F$ : en la sangre se han cebado $M L S$

65 de las TFMLS : las $U$

68 apartaron TFMLS : apartaran $U$

69 guardaron TFMLS : guardaran $U$ : quedaron, tachado $M$

70 manadas TFMLS : majadas $U$

71 derramadas TFMLS : apartadas $U$

79 ninguna $T M L S$ : ninguno $F U$

79 sabor TUFMS : señor $L$

80 y $T:$ y en $U F M L S$

80 quexan TUFS : aquexan $M L$

81 prueban TUMSL : ponen $F$

84 arma y sus $T F$ : arma, a sus $U:$ arma, y a sus $M: \operatorname{armas}$ y a sus $L: \operatorname{armas}$ y sus $S$

85 el ageno sangre entregan TFM : la agena sangre entriegan $U:$ el ageno sangre estragan $L$ : en su sangre se entregão $S$

88 destruido TUFML : distraído $S$

89 perdido TUFLS : tenido $M$

91 estendieron TFMLS : estendieran $U$

96 vinieren $F S$ : vinieron $T$ : viniessen $M$ : venieran $L U$

101 de si TUM : de ti FLS [La lectura de ti es lectio facilior, probable enmienda innecesaria y adoptada independientemente. 'Ausentarse de si' hay que entenderlo como 'por sí mismo, por su propia cuenta'.

102 tiénente $T F M L$ : tiente $S$ : teniéndote $U$

108 siempre con crueza $T$ : siempre crueza FUMLS

RFE, LXXXVII, $2 .^{\circ}, 2007$, págs. $323-350$, ISSN: 0210-9174 
111 hazes TFMLS : usas $U$

116 nombrar $T$ : llamar $U F M L S$

117 y de otros eres criado $T M L$ : siendo de otros $U:$ y de otro eres criado $F:$ y de otros eres mandado $S$

118 Liberalidad $M T U$ : La libertad simple $F:$ La liberalidad $S:$ La libertad $L$

119 Y pides $T$ : Pides $U F M S L$

121 y a todos la alma $T M S:$ y el alma a todos $U$ : y a todos el alma $F L$

122 y haces TUML : hazes $F S$

123 y aborreces TFMLS : aborreces $U$

124 y en todo $T F M$ : en todo $U L S$

128 lo TUMLS : el F

130 andas $T M$ : vives $U F L S$

131 para $T U M S$ : por $F L$

133 tus ovejas de un TMLS : tus ovejas a montón $U$ : las ovejas de tu $F$

134 cuales TUFML : cuántas $S$

$135 \mathrm{ni}$ lo entiendes ni te entiendes TFMLS : ni te entienden ni te entendes $U$

136 es TUML : sin FS

143 Quedarás león TUFLS : Pues león quedas $M$

144 entre $T U F$ : entr'el $M L S$

$146 \operatorname{dos} M T U S L: \operatorname{diez} F$

149 De la razón te agenas TUM : De la razón te enagenas $F S$ : Das la razón en agenas $L$

153 ganar UMLS : goardar $T$ : tomar $F$ [La lectura ganar, a pesar de no ser la del texto base, parece ser la correcta.

154 soberbios $T U$ : soberbos $F M L S$

158 perdieron $T U F$ : perderan $M L$ : perdierão $S$

159 su señorío $T U$ : tu señorío $F M L S$

165 males, a otros $L$ : mal, a otros TUMS : mal y a otros $F$ [Acepto la enmienda de L, que además de restituir la medida, permite la correlación males-bienes.

166 lo para ques $M$ : pera lo que es TFL : lo para queres $U$ : lo pera que es $S$ [acepto la lectura de $\mathrm{M}$, lectio difficilior y probablemente correcta a la vista de $\mathrm{U}$ y $\mathrm{S}$, que han intentado enmendar sin tanta fortuna como TFL. El sentido es 'a nadie ordenas aquello para lo cual es (=esta destinado, le es apropiado...)'.

168 tu guía TUMLS : guía $F$

170 y con FUMLS : con T

171 había TFM : tenía $U L S$

173 entregases TFMLST : entergaises $U$

175 haber TFMLS : leer $U$

177 del sangre TM : de sangre UFS : de la sangre L [la lectura correcta es la del texto base, por más que parezca lo contrario. Se trata de un lusismo que los otros testimonios han intentado enmendar.

178 viesses TUML : diesses FS

181 Si $T U$ : Y si FMLS

185 y que con sus TUFS : y con sus $M L$

187 vezinos y estrangeros $T$ : vezinos estrangeros $U F M L S$

189 Qué fuera dar muchas vueltas TMLS : Te hizieron dar muchas vueltas $U$ : Que fueron dar muchas vueltas $F$

191 que hasta el TMLS : porque a un $U$ : que hasta un $F$

192 si $T U F S$ : se $M L$

194 Al gobierno el pastor venga TMLS : El gobierno un pastor tienga $U$ : Al gobierno un pastor venga $F$ 
196 y el TUMLS : el $F$

198 uno TUMLS : cual $F$

199 uno TMLS : cual FU

206 pasaras $T U F L$ : pasarán $M S$

208 van $T U F L S:$ ven $M$

210 y tú ni TFMLS : y tú no $U$

215 los dulces ríos gustando TUMLS : tu manada deseando $F$

216 remotos y los cercanos TUMLS : los remotos y cercanos $F$

219 tienes TUMLS : y tienes $F$

222 hazen menos amado TUMS : haze menos amado $L$ : has menoscabado $F$

223 lo que has aprendido $T:$ lo aprendido $U F M L S$

225 y el TFMLS : con $U$

227 apártate ahora TMLS : también te aparta $U$ : apártate ya $F$

229 que de vierte $T S:$ pues de verte $U$ : ya que de ver $F:$ y que de verte $M L$

230 si de lexos TUFML : y si de lexos $S$

236 en pieles de tus $T M L S$ : en peleyos de $U$ : con pieles de tus $F$

237 los lobos bravos y fieros TFMLS : lobos rabiosos y fieros $U$

240 cuan otro mudado MTLS : cuanto mudado ya $F$ : cuando otros mudado $U$

243 de no te veres $M T U L S:$ de te no vieres $F$

244 siento MLTUS : cuento $F$

245 presunción $T U L S$ : oración $F$ : pensamiento $M$

249 que tienen otros TFMLS : dar a los tuyos $U$

253-261 Estrofa dislocada en $M$, entre los vv. 234-235

255 en todo ha menguado TUML : anda enagenado $F$

257 deseas TFML : te deseas $U$ : le deseas $S$

258 te $T U M L:$ me $F S$

259 porque $T U F L S:$ por $M$

260 y aun mejor es que te TUMLS : que mejor es que $F$

264 ganarte $T U L S$ : guardarte $F M$

265 a quien $T U L S:$ de quien $F M$

265 usurpado TUFLS : engañado $M$

\section{Aviso segundo}

Título Segundo aviso de Franco a su amigo Sebasto TM : Outro aviso de Franco a Sebasto $U$ : Estas se fizeram a el-rei dom Sebastião quando se queria ir para África a segunda vez $L$

13 tu locura y sus tormentos $T M$ : sus locuras y tromentos $U$ : con locura sus tormentos $L$

14 los pastores que han ganado $T M L:$ y los pastores que han adquerido $U$

15 ageno pasto y ganado TUM : om $L$

17 con el suio tan querido TUL : con el favor tan querido $M$

26 mete la mano en tu seno UML : om $T$

27 señorío $T U M$ : poderío $L$

28 bastara MTL : basta $U$

29 se viesses como pareja $T M:$ si visses como empareja $U$ : si viesses como se apareja $L$

30 que el que a guerra t'aconseja TUM : cual es que ahora te aconseja $L$

33 y más de guerra supiesses $T U$ : de la suerte que quisiesses $L:$ om $M$

35 pues tu edad al exercicio $T M L$ : om $U$

39 juro a diez que pienso halla $T L:$ y es porque pienso que halla $U M$ 
41 Después que echó bendición TUL : om $M$

43 de odio $T L$ : odio $U M$

44 y pegóte su dolencia $U$ : apegóte su delencia $T L$ : y pegóte la dolencia $M$

47 Oh, cuántas $M L$ : cuántas $T U$

50 Mas dél $M$ : Mas él $T$ : Mal dél $L$ dizían $T M L:$ diz uno $U$

51 los que $T M L:$ los cuales $U$

52 se informaban $T L$ : perguntaban $U M$

56 esto TUM : om $L$

60 a buscar $T L$ : buscar $U M$

61 quizá harán dél mudado $T$ : quiçá lo hallarás mudado $U M$ : quizá hallarás mudado $L$

62 vinieres $T L$ : viniesses $U M$

63 no te darán el lugar $T L$ : puede no te dar lugar $U$ : no te dará el lugar $M$

64 en ires $T M L$ : en tu ida $U$

65 ninguno TUM : ningún $L$

67 pues viven los que esto asiertan $T M$ : pues viven los que esto assiento $U$ : pues no viven los que aciertan L [Puesto que T y M escriben también aciertan, parece una inhábil rima con la misma palabra que además no tiene sentido en el v. 67. U ha intentado subsanar el aparente error, pero destruyendo la rima (aunque a su vez su lectura es posiblemente resultado de un error sobre asientan. Por su parte, L corrige mejorando el sentido, pero manteniendo la improbable repetición de palabra. En realidad es algo más sencillo: el verso 67 no tiene que rimar con el 65, sino con el 64: conciertan la palabra castellana correcta es asertan, 'afirman', que mediante un diptongo hipercorrecto típico de los portugueses que escriben castellano, se transforma en asiertan, y que pese a su incorrección tenemos que conservar.

69 le da $T M L:$ se da $U$

71 Y todo su prevenir TUM : om L

76 que el mal que te agora $T:$ y huy del mal que te $U$ : que el mal que agora te $M L$

78 grande $T:$ gran $U M L$

81 sobra $T U M$ : sobre $L$

86 y porque me halles razón TUM : y porque me halles con razón $L$

87 mismo la $T M L$ : la misma $U$

88 que hasta ahora tienes hecho TML : que tú hasta agora has hecho $U$

89 de los que en su propio lecho TUM : om $L$

90 no sueñan ser lo que son $T L:$ no soñaron cuales son $U M$

91 Como bien ... muy gran celo TML : om $U$

97 sabor $T U M$ : saber $L$

98 lo van a abrir o cerrar $T$ : todo lo van a mandar $U M$ : lo van a abrir y cerrar $L$

99 mostrándote muy gran celo $T M L$ : desse engañado deceo $U$

100 mas ya que $T M L:$ mas ay que $U$

103 de justicia $T M L$ : la justicia $U$

104 Cayo, Nerón y Antonino $T$ : Cayo, Nerón, Antonino $U M$ : E Layo, Nero y Antonino $L$

106 han sido ministros $T L$ : ha sido ministro $U M$

107 en su TUM : su $L$

113 cuidado $T M L$ : el cuidado $U$

115 pues no $T U M$ : pues que no $L$

117 al pueblo $T L$ : el pueblo $U M$

121 el mal TUM : al mal $L$

122 recio y $T U M:$ y recio $L$

123 sigue TUM : hace $L$ fado $M$ : hado TL [La lectura de $\mathrm{M}$, además de resultar en la correcta medida del verso, permite el juego de palabras fadolenfadarse, sin duda intencional. 
125 que muchacho y mal dispuesto $T M$ : que eres muchacho e indispuesto $U$ : mas, muchacho y mal dispuesto $L$

126 no lo harás sin grande $T M$ : no busques alguna pena $U$ : no te hallarás $\sin$ gran $L$

127-135 $M$ disloca esta estrofa, última del poema original, para colocarla entre los vv. $72-73$

127 te hablé $T M$ : hablé $U$ : te he hablado $L$

128 de escrebir $T M$ : te dizir $U$ : escrebir $L$

130 hallé TUM : he hallado $L$

135 temas TUM : teimas $L$

136-171 Texto exclusivamente en $L$

\section{Aviso tercero}

Título Aviso tercero $T$ : Tercero aviso de Franco a su amigo Sebasto $M$ : Otro aviso de Franco a su amigo Sebasto $U$

$1 \mathrm{Di}$, pastor, tú por ventura $T$ : Hão, pastor, tú por ventura $M U$ [El convencional hão, corriente del sayagués en la poesía pastoril castellana es probablemente la lectura del original, como lectio difficilior, y es también la versión que da Barbosa Machado. Sin embargo, por motivos de consistencia metodológica, mantengo la lectura del texto base, igualmente correcta.

2 duermes o $T:$ duermes, di, o $M$

6 deseches TUM : desprecies Barbosa Machado

7 de tu buen amigo Franco TM : om. $U$

12 querrá $T$ : quiera $U M$

13 como lo $T M$ : como $U$

14 vejo $T U$ : veo $M$

15 y $T U:$ om $M$

18 le $T U:$ lo $M$

20 trasquilar contra $T$ : también contra $U$ : dexo ser contra $M$

21 y querer hazer $T:$ querer hazer tu $U M$

25 ve si hay daño más terrible $T M$ : era harto aborrecible $U$

27-36 texto solo en $T U$

31 en $\operatorname{cosas} T$ : en $\operatorname{cosa} U$

32 queste las ha de tragar $T:$ que es quien las ha de tragar $U$

33 haze $T$ : y haze $U$

35 la repasta : las repasta TUM [El texto conservado no tiene sentido, según queda dicho en la nota correspondiente.

40 le era $T M$ : le es $U$

47 como de pastor y amigo $T$ : como de tu pastor y amigo $U$ : como pastor y amigo $M$

50 temporada $T M$ : temperada $U$

53 y en el invierno : y en invierno $T U$ : en el invierno $M$

59 tan embelesado $T M$ : te han $U$

62 eras $T$ : eres $U M$

$64 \mathrm{Si}$ al provecho, si al servicio $T$ : el provecho y el servicio $U M$

72 vendrá aun $T M$ : aun vendrá $U$

75 agradece $T U$ : agradécele $M$

78 tus $T M$ : a tus $U$

79 oirás $T M:$ y oirás $U$

83 yo $T M$ : ya $U$

84 montaña $T M$ : cabaña $U$ 
90 las $T U: \operatorname{los} M$

91 trasquilada $T M$ : trasquilados $U$

94 otra lana prestada $T M$ : otras emprestadas $U$

95 el mal tiempo $T M$ : el invierno $U$

96 llevaron $T$ : llevaran $U M$

97 y $T:$ el $U M$

100-108 El ganado...provecho $M:$ om $T U$

112 al $T U:$ el $M$

113 sus $U M$ : tus $T$

115 atupan : otupan $U$ : atupen $M$ : otupen $T$ [Cada una de las versiones presenta un problema. T, apesar de ser el texto base, presenta dos problemas: el comienzo en o- en lugar de la a-corriente en portugués, y la conjugación, que debe ser como la de 'tupir'. De ahí la lectura hibrida que propongo: el verbo de $M$, aceptable en cuanto lusismo, y la conjugación de $U$.

118 Con esto $U$ : Con estes $T$ : Que en esto $M$

122 a tu $T:$ de tu $M U$

125 la tratas $T M$ : las tratas $U$

126 cayada $M$ : cayado $T U$

129 que unos tus $T:$ unos tus $M:$ que unos sus $U$

130 ceño : cieno $T$ : señorío $U$ : seno $M$ [No hay ningún error, sino que cada uno de los testimonios intenta enmendar de diferente forma la palabra que no entiende en el original.

136 viste $T M$ : oiste $U$

137 todo $T:$ todos $U M$

148 aprisco $T M$ : chico $U$

149 pastor $T M$ : pues $U$

152 los $T U$ : tus $M$

153 ensanchares tu cabaña $T M$ : ensanchar a tus cabañas $U$

158 que si sordo no estuvieses $M T$ : que si cuerdo tú estuvieses $U$

160 tanto ruego $T M$ : tantos ruegos $U$

168 ojeas $T$ : oteas $U M$

173 hato $M U$ : harto $T$

182 voltear el : voltar el $T$ : volver el $U$ : voltar tu $M$ [Hay que entender que el lusismo voltar de $\mathrm{T}$ y $\mathrm{M}$ es un error, pues no está en lugar de su equivalente léxico en castellano, volver (como interpreta U), sino en el de su parecido 'voltear' (hacer girar el cayado en el aire para castigar a los malos ministros).

186 tan poco $T M$ : cuan poco $U$

187 que $T:$ y $U M$

188 en día $M:$ día $T U$

190 por despoblados $M U$ : por te despoblados $T$

193 cortos sus : cortos tus TM : ciertos sus $U$ [Ninguna de las lecturas tiene sentido, de ahí la necesidad de una enmienda que las una: los zagales llevan al pastor por despoblados porque dentro de la aldea sus poderes son menores.

200 y el $U:$ y otro $T:$ del otro $M$

209 por su $M U:$ por $T$

216 dignidad $T M$ : christiandad $U$

217 dia sancto $T U$ : disanto $M$

219 cubrirte $T U$ : vestir $M$

219-220 TU : (orden invertido) $M$

222 y lanas de mil colores $T M$ : con muy diversas colores $U$ 
225 zagales y pastores $U M$ : zagalas y pastoras $T$ [Aunque cualquiera de las dos versiones tendría sentido, lo tiene más la versión editada, aparte de que sólo así se mantiene la rima. Es muy notable, sin embargo, que T haya introducido esta enmienda.

228 en ti : ti TUM

229 les $T: \operatorname{los} U M$

232 te ver $T M$ : verte $U$

234 gemidos $T M$ : en gemidos $U$

235 yo no sé $T M:$ no sé $U$

244 de $T: \operatorname{del} M U$

246 porqueste $U M$ : porque $T$

250 si es cuerdo, si bobo $T$ : si es cuerdo, si es bobo $M$ : si es cordero o lobo $U$

253 oído $M U$ : sabido $T$

254 cumple a ti darle el remedio $T$ : cumple a ti darte remedio $U$ : a ti cumple darle el medio $M$

257 Yo $T M:$ mas $U$

258 aviso $T U$ : consejo $M$

259 engaña $U$ : daña $T M$

260 daña $U$ : engaña $T M$

260 te...te $M U$ : se...se $T$ [Los vv. 259-260 han sufrido la enmienda de TU o su subarquetipo, que no parece haber captado el sentido del original, creando un sinsentido.

262 con atención $M U: \sin$ afición $T$

265 su $T M$ : tu $U$

268 te es más $T M$ : tienes $U$

271-274 Pouca...verdades $M$ : om TU 